Volume. 8 Nomor. 2, Mei 2021. p - 2354-8649 I e - 2579-5767

Open Access at: http://ojs.umrah.ac.id/index.php/selat

DOI: https://doi.org/10.31629/selat.v8i2.3537

\title{
PERAN TENTARA NASIONAL INDONESIA ANGKATAN LAUT DALAM PERWUJUDAN GOOD ORDER AT SEA: STUDI KASUS ALUR LAUT KEPULAUAN INDONESIA II
}

\author{
I Gde Padang Suryawan ${ }^{1}$, Suharto Ladjide ${ }^{2}$, Sayed Fauzan Riyadi ${ }^{3}$ \\ ${ }^{12}$ Sekolah Staf dan Komando Tentara Nasional Indonesia Angkatan Laut \\ Jalan Ciledug Raya No. 2, Komplek Seskoal, RT.4/RW.11 \\ suryawan_igp@hotmail.com, suharto@idu.ac.id \\ Cipulir, Kebayoran Lama, Kota Jakarta Selatan, Provinsi DKI Jakarta 12230, Indonesia \\ ${ }^{3}$ Fakultas Ilmu Sosial dan Ilmu Politik Universitas Maritim Raja Ali Haji \\ Jalan Raya Dompak Tanjungpinang Kepulauan Riau \\ sayedfauzan@umrah.ac.id
}

\begin{abstract}
The Archipelagic Status of Indonesia given under UNCLOS 1982 has both rights and responsibilities. one of those responsibilities is Indonesia has to provide sea lanes for freedom of navigation in the form of Indonesia Archipelagic Sea Lanes (ALKI). In recent developments, Indonesia as Coastal State also has a responsibility to maintain good order at sea, especially along Its ALKI. This paper examined how the Indonesian Navy, especially the Second Fleet Command, plays its role in maintaining maritime security di ALKI II. The result shows that the Indonesian Navy has sufficient legal basis to perform good order at sea. Besides that, the Second Fleet Command also has proved its commitment to pursue good order ats sea with comprehensive, systematic and routine actions along ALKI II.
\end{abstract}

Keywords; UNCLOS 1982, Good order at sea, Indonesian Navy, ALKI, Maritime Security

\begin{abstract}
Abstrak
Status Indonesia sebagai Negara Kepulauan dalam UNCLOS 1982 memberikan hak sekaligus kewajiban. Salah satu kewajiban tersebut adalah menyediakan jalur navigasi untuk lintas damai yang berupa Alur Laut Kepulauan Indonesia (ALKI). Dalam perkembangannya Indonesia sebagai negara pantai juga memiliki kewajiban untuk mewujudkan good order at sea, terutama disepanjang ALKI. Tulisan ini melihat bagaimana peran Tentara Nasional Indonesia Angkatan Laut (TNI AL), khususnya Komando Armada II dalam melaksanakan pengamanan di ALKI II. Hasil pembahasan menunjukkan bahwa TNI AL memiliki dasar hukum yang memadai untuk melaksanakan perwujudan good order at sea. Selain itu Komando Armada II telah membuktikan komitmennya untuk mewujudkan good order at sea secara komprehensif, sistematis dan rutin di sepanjang ALKI II.
\end{abstract}

Kata Kunci; UNCLOS 1982, Good order at sea, TNI AL, ALKI, Keamanan Maritim 


\section{PENDAHULUAN}

Indonesia mendapatkan pengakuan dunia internasional sebagai negara maritim melalui pengesahan United Nations Convention on Law of the Sea (UNCLOS 1982) pada tahun 1982. Melalui konvensi tersebut, Indonesia masuk ke dalam kategori negara kepulauan (Archipelagic State). Status ini merupakan buah perjuangan diplomasi internasional Indonesia yang dimulai sejak Deklarasi Djuanda pada tanggal pada 13 Desember 1957. Setelah sebelumnya wilayah perairan antar pulau-pulau utama Indonesia merupakan laut bebas (high seas), maka melalui deklarasi tersebut Indonesia melakukan klaim bahwa perairan dalam merupakan bagian dari wilayah teritorial.

Secara khusus pengaturan mengenai Negara-Negara Kepulauan diatur dalam Bab IV Pasal 46 sampai Pasal 54 UNCLOS 1982. Keuntungan Indonesia, selain menguasai perairan dalam menjadi Laut Teritorial, adalah penentuan zona-zona lainnya seperti Zona Ekonomi Eksklusif (ZEE) diukur dari garis pangkal kepulauan. Artinya luas wilayah laut Indonesia berdasarkan UNCLOS 1982 adalah sebesar 5,9 juta $\mathrm{km}^{2}$, yang mencakup 3,2 juta $\mathrm{km}^{2}$ laut teritorial dan 2,7 $\mathrm{km}^{2}$ Zona Ekonomi Eksklusif.

Disisi lain, terdapat juga kewajiban-kewajiban Negara-Negara Kepulauan. Pasal 51 UNCLOS 1982 mengatakan bahwa Negara-Negara Kepulauan "harus menghormati perjanjian yang ada dengan Negara lain dan harus mengakui hak perikanan tradisional dan kegiatan lain" bagi negara-negara tetangganya. Selain itu juga "harus menghormati kabel laut yang ada yang dipasang oleh Negara lain dan yang melalui perairannya tanpa melalui darat. Suatu Negara kepulauan harus mengijinkan pemeliharaan dan penggantian kabel demikian."

Kewajiban lain yang utama adalah hak berlayar bagi kapal-kapal berbendera asing melalui wilayah teritorial Indonesia. Pasal 52 UNCLOS 1982 menegaskan "kapal semua Negara menikmati hak lintas damai (right of innocent passage) melalui perairan kepulauan". Kemudian Pasal 53 UNCLOS 1982 mengatur tentang hak lintas alur laut kepulauan (right of archipelagic sea lanes passage), yaitu hak kapal dan pesawat udara asing untuk melakukan pelayaran atau penerbangan sesuai dengan 
ketentuan-ketentuan Konvensi dengan cara normal hanya untuk melakukan transit yang terus menerus, langsung, dan secepat mungkin serta tidak terhalang. ${ }^{1}$

Atas dasar tersebut Pemerintah Indonesia telah menetapkan Alur Laut Kepulauan Indonesia (ALKI) sebagai jalur perlintasan kapal-kapal asing, melalui Peraturan Pemerintah Nomor 37 Tahun 2002 tentang Hak Dan Kewajiban Kapal Dan Pesawat Udara Asing Dalam Melaksanakan Hak Lintas Alur Laut Kepulauan Melalui Alur Laut Kepulauan Yang Ditetapkan. Salah satu ALKI yang ditetapkan adalah ALKI II yang berada di wilayah tengah Kepulauan Indonesia, mulai dari Selat Lombok di sisi selatan hingga Laut Sulawesi di sisi utara.

Implementasi hak dan kewajiban ALKI ini bertujuan untuk menciptakan good order at sea, sebagaimana disampaikan oleh Till mengutip The Royal Navy "tindakantindakan yang dilakukan oleh pihak militer melalui kerja sama dengan institusiinstitusi pemerintahan lainnya, agensi-agensi dan mitra-mitra internasional dalam lingkungan maritim untuk mengatasi kegiatan illegal dan mendukung kebebasan di laut, dalam rangka melindungi kepentingan nasional dan internasional."2 Dari pengertian tersebut, maka jelas Indonesia memiliki hak dan kewajiban menjaga keamanan pelayaran kapal-kapal asing yang melintas di ALKI.

Tulisan ini melihat sejauh mana peran Tentara Nasional Indonesia Angkatan Laut (TNI AL) dalam mewujudkan good order at sea, khususnya di ALKI II. Pemilihan ALKI II sebagai studi kasus didasari oleh pertimbangan bahwa ALKI II, walaupun tidak sepadat ALKI I, namun merupakan jalur ALKI yang paling sedikit bersentuhan dengan perbatasan laut antara Indonesia dengan negara-negara tetangganya, sebagaimana terlihat dalam Gambar 1. dengan demikian maka hak dan kewajiban Indonesia adalah lebih dominan dibandingkan ALKI I dan ALKI III.

\footnotetext{
${ }^{1}$ Atje Misbach Muhjiddin, Status Hukum Perairan Kepulauan Indonesia dan Hak Lintas Kapal Asing, Bandung: Penerbit Alumni, 1993, hlm. 186.

${ }^{2}$ Geoffrey Till, Seapower: A Guide for the Twenty-First Century (4th ed.). Routledge, 2018, https://doi.org/10.4324/9781315621210, hlm. 286.
} 


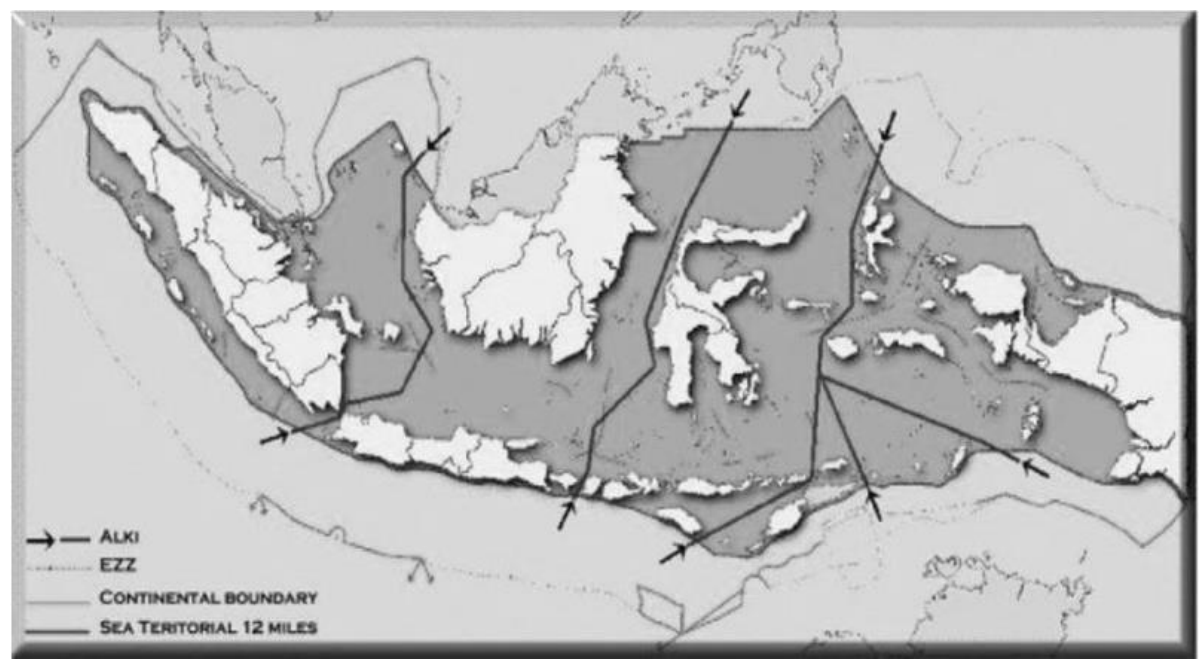

Gambar 1 Peta Alur Laut Kepulauan Indonesia

Sumber: Wulan Pri Handini \& Danang Risdiarto, "Kedaulatan Wilayah Udara Di Atas Alur Laut Kepulauan Indonesia (ALKI)", Jurnal Rechts Vinding Volume 8, Nomor 2, Agustus 2019, hlm. 281.

\section{METODE}

Penelitian pada dasarnya merupakan tahapan untuk mencari kembali sebuah kebenaran. Sehingga akan dapat menjawab pertanyaan-pertanyaan yang muncul tentang suatu objek penelitian. ${ }^{3}$ Metode penelitian yang akan dilakukan oleh penulis adalah penelitian yuridis empiris yaitu penelitian hukum yang dikonsepkan sebagai pranata sosial secara empiris yang berdasarkan data sekunder sebagai data awal kemudian dilanjutkan dengan data primer atau data yang diperoleh dari lapangan. ${ }^{4}$ Penelitian hukum empiris dapat disebut juga dengan penelitian sosiologis yang mana penelitian ini mengkaji antara fenomena hukum yang terjadi di masyarakat dan dengan apa yang di kehendaki oleh Peraturan Perundang-undangan serta teori-teori hukum.

\section{PEMBAHASAN}

\subsection{Good Order at Sea dalam Tinjauan Hukum Internasional}

Bateman, Ho dan Chan mendefinisikan good order at sea sebagai "memastikan keamanan dan keselamatan pelayaran dan memastikan negara dapat mengejar kepentingan maritimnya dan menggunakan sumber daya maritimnya secara

\footnotetext{
${ }^{3}$ Bambang Sunggono, Metode Penelitian Hukum, Jakarta: Raja Grafindo Persada, 2001, hlm. 29.

${ }^{4}$ Amiruddin and Zainal Asikin, Pengantar Metode Penelitian Hukum, Jakarta: Raja Grafindo Persada, 2003, hlm. 132
} 
berkelanjutan dan damai sesuai hukum internasional."5 Pasal 19 UNCLOS 1982 menyebutkan "good order" dalam pendefinisian hak lintas damai (innocent passage): "Passage is innocent so long as it is not prejudicial to the peace, good order or security of the coastal State. Such passage shall take place in conformity with this Convention and with other rules of international law." Dari dua argumen di atas, maka good order at sea, terutama terkait hak lintas damai merupakan subjektivitas negara pantai (coastal state), namun tetap mengacu kepada hukum internasional.

Selain UNCLOS 1982, keberadaan ALKI diatur melalui The International Maritime Organization (IMO) Maritime Safety Committee Resolution MSC 72(69). Ancaman terhadap good order at sea, seperti terjadinya kecelakaan kapal diatur dalam SOLAS Convention, terkait pencegahan pencemaran dan perlindungan lingkungan laut sebagaimana diatur dalam MARPOL Convention, dan berbagai konvensi IMO lainnya.

\subsection{Dasar Hukum Peran dan Gelar Pasukan TNI AL di ALKI II}

Berdasarkan Pasal 9 Undang-Undang Nomor 34 Tahun 2004 tentang TNI, TNI AL memiliki tugas untuk:

1. Melaksanakan tugas TNI matra laut di bidang pertahanan;

2. Menegakkan hukum dan menjaga keamanan di wilayah laut yuridiksi nasional sesuai dengan ketentuan hukum internasional yang telah diratifikasi;

3. Melaksanakan tugas diplomasi angkatan laut dalam rangka mendukung kebijakan politik luar negeri yang ditetapkan pemerintah;

4. Melaksanakan tugas tni dalam pembangunan dan pengembangan kekuatan matra laut; dan

5. Melaksanakan pemberdayaan wilayah pertahanan laut.

Dalam melaksanakan tugas pokoknya, TNI AL menggunakan Doktrin Jalesveva Jayamahe sesuai Keputusan Panglima Tentara Nasional Indonesia Nomor Kep/503/V/2018 tentang Doktrin TNI Angkatan Laut Jalesveva Jayamahe. Secara khusus terkait wilayah ALKI diatur dalam Keputusan Panglima TNI Nomor

\footnotetext{
${ }^{5}$ Sam Bateman, Joshua Ho, dan Jane Chan, "Good Order at Sea in Southeas Asia” RSIS Policy Paper, 2009, hlm.7
} 
154 I Gde Padang Suryawan, Suharto Ladjide, Sayed Fauzan Riyadi, Peran Tentara Nasional ...

Kep/1067/XII/2016 tanggal 15 Desember 2016 tentang Petunjuk Operasi Pengamanan Alur Laut Kepulauan Indonesia.

Untuk wilayah ALKI II, gelar pasukan TNI AL berada di bawah Komando Armada II yang berkedudukan di Surabaya. Sebagai Kotama Operasi Komando Armada II memiliki tugas pokok menyelenggarakan operasi intelijen maritim guna mendukung pelaksanaan operasi laut, menyelenggarakan operasi tempur laut dalam rangka OMP (Operasi Militer Perang) baik operasi gabungan maupun mandiri, dan menyelenggarakan OMSP (Operasi Militer Selain Perang) baik berupa operasi laut sehari-hari maupun operasi keamanan laut di wilayahnya sesuai dengan kebijakan Panglima TNI. Untuk melaksanakan hal ini dilaksanakan tugas-tugas:

1. Membina kemampuan dan kekuatan komponen Sistem Senjata Armada Terpadu (SSAT),

2. Membina kemampuan peperangan laut,

3. Membina kesiapan operasional untuk melaksanakan OMP dan OMSP dalam rangka pengendalian laut serta proyeksi kekuatan ke darat lewat laut dalam rangka penegakan kedaulatan dan hukum di laut sesuai kebijakan Panglima TNI serta,

4. Membina potensi maritim menjadi kekuatan pertahanan dan keamanan negara di laut yang berkedudukan di bawah dan bertanggung jawab kepada Kasal.

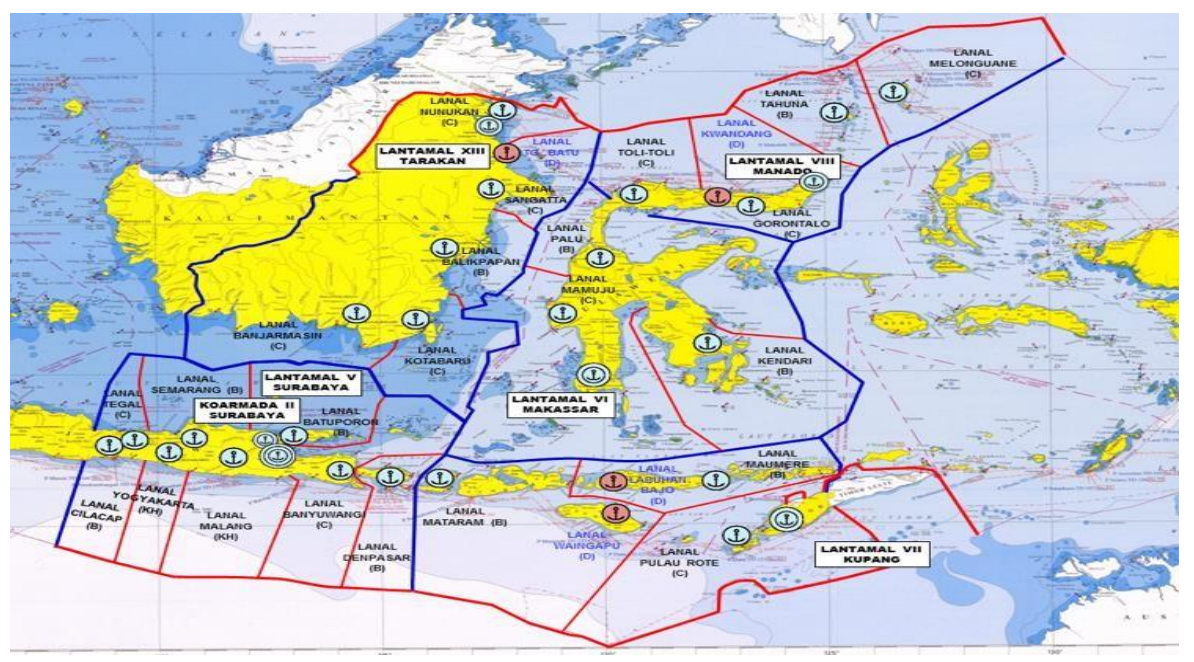

Gambar 2 Wilayah Kerja Komando Armada II Sumber: Komando Armada II 
Wilayah kerja Komando Armada II berada sepanjang ALKI II dengan didukung oleh 5 (lima) Pangkalan Utama TNI AL dan 23 Pangkalan TNI AL, seperti tersaji dalam Gambar 2. Komando Armada II memiliki motto Ghora Wira Madya Jala yang berarti "ksatria perkasa di tengah samudera".

\subsection{Analisa Peran TNI AL Terkait Good Order at Sea di ALKI II}

Geoffrey Till membagi dimensi "good order at sea" ke dalam lima hal yang tujuannya memenuhi peran kelautan sebagai kepentingan nasional dan internasional sesuai UNCLOS 1982 dan konvensi hukum internasional lainnya, seperti dalam Gambar 3.

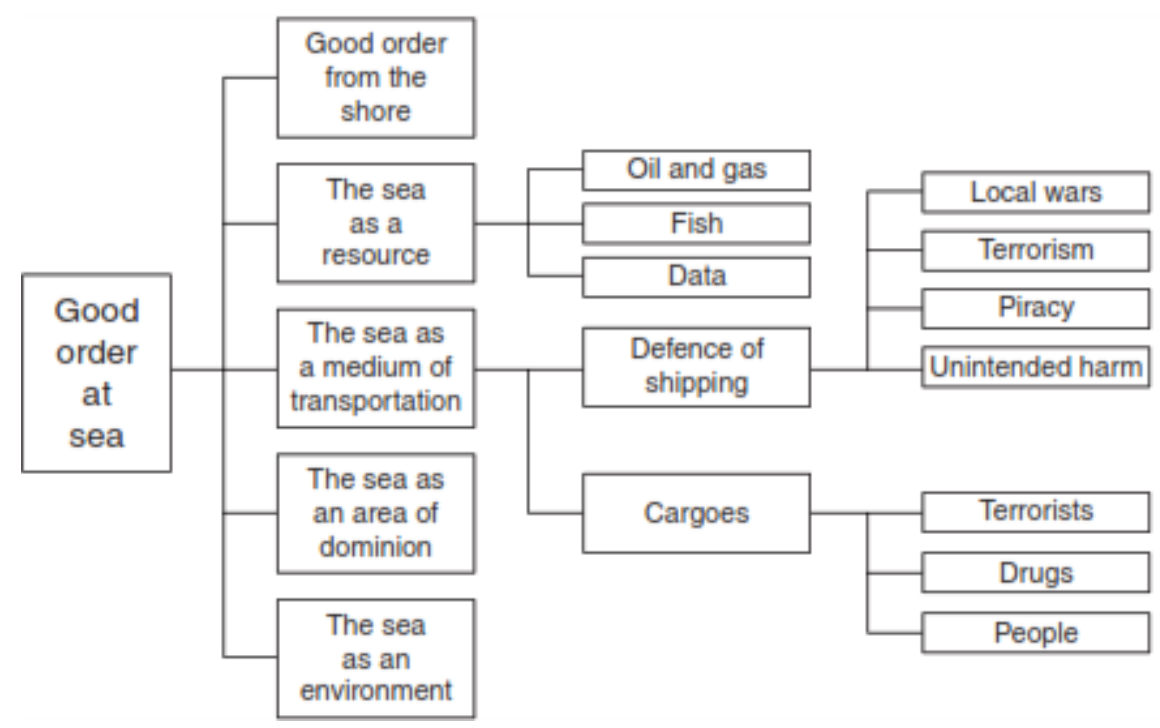

Gambar 3 Dimensi Good Order at Sea

Sumber: Geoffrey Till, Seapower: A Guide For The Twenty-First Century Second Edition. (Oxon: Routledge,2009), hlm. 287.

Bagian ini selanjutnya akan mendeskripsikan peran TNI AL, khususnya dibawah kewenangan Komando Armada II sesuai dimensi di atas.

a. Good order from the shore, saat ini Komando Armada II memiliki fungsi intelijen dan potensi maritim sebagai garda terdepan dalam deteksi dini dan penggalangan potensi masalah yang akan mengganggu terwujudnya good order at sea di ALKI II.

b. The sea as a resource, wilayah ALKI II selain sebagai jalur navigasi juga terdapat produksi Migas, terutama di wilayah Kalimantan Timur. Di sisi 
156 I Gde Padang Suryawan, Suharto Ladjide, Sayed Fauzan Riyadi, Peran Tentara Nasional ...

lain, sumber daya perikanan yang ada di ALKI II termasuk ke dalam Wilayah Pengelolaan Perikanan Negara Republik Indonesia (WPP NRI) 713 dan 716 yang dimanfaatkan oleh nelayan tradisional dan modern. Dalam gelar operasi Komando Armada II melakukan deteksi dan pengejaran, penangkapan dan penyelidikan (Jarkpalid) terhadap kapal perikanan yang diduga melakukan pelanggaran hukum.

c. The sea as medium of transportation, ALKI II berdasarkan data identifikasi AIS, dilitasi oleh lebih 424 ribu kapal setiap tahunnya. Gelar operasi Komando Armada II melakukan identifikasi terhadap potensi gangguan keamanan dan keselamatan navigasi sepanjang ALKI II. Salah satu hotspot adalah di sekitar Laut Sulu-Sulawesi. Pada tanggal 16 Januari 2020, terjadi penculikan dan penyanderaan terhadap lima WNI yang bekerja di kapal ikan berbendera Malaysia di perairan Pulau Tambisan, Lahad Datu Malaysia oleh Kelompok Abu Sayyaf. Merespon hal ini gelar operasi khususnya Patkor Indomalphi-20 TNI AL-Tentara Laut Diraja MalaysiaPhillipine's Navy dilaksanakan secara rutin.

d. The sea as an area of dominion, penggunaan ALKI juga diizinkan untuk kapal perang negara asing, namun tetap menganut prinsip lintas damai. Selama tahun 2020, Komando Armada II melakukan pendeteksian dan pengawasan terhadap USNS John Ericsson, USS Ronald Reagan \& USS Antietam (Amerika Serikat), serta KD Paus-3507 dan KA Tun Azizan (Malaysia).

e. The sea as an environment, perlindungan lingkungan laut juga menjadi aspek keamanan maritim. Oleh karena itu Komando Armada II dalam gelar operasinya berupaya melakukan pencegahan dan penindakan hukum terhadap kapal-kapal yang dicurigai melakukan pencemaran di laut.

Komitmen Komando Armada II dalam mewujudkan good order at sea terbukti dengan gelar operasi yang membagi ALKI II menjadi 10 sektor patroli kapal laut dan tiga sektor patroli pesawat udara. Secara keseluruhan, selama tahun 2020 total hari operasi kapal dan pesawat udara adalah sebanyak 1.634 hari. Sedangkan unsur- 
unsur yang dilibatkan mulai dari Kapal KRI dan Alpung TNI AL lainnya, pesawat udara dan kekuatan pendukung lainnya.

Dari hasil deksripsi di atas, terlihat bahwa perwujudan good order at sea oleh Komando Armada II dilaksanakan secara komprehensif, sistematis dan rutin. Namun bukan berarti hasil yang diperoleh tidak ada kekurangan. Beberapa catatan terhadap pelaksanaan pengamanan ALKI II antara lain menuntut adanya dukungan politis dan teknis yang lebih besar, peningkatan kualitas dan kuantitas Alutsista TNI AL beserta sarana prasarana pendukung. Kemudian yang tidak kalah penting adalah pemahaman bahwa kewajiban negara pantai dalam mewujudkan good order at sea adalah tuntutan dunia internasional berdasarkan hukum internasional. Oleh karena itu kapasitas institusi negara, baik militer maupun sipil, adalah penentunya. Boleh saja memiliki kewenangan yang spesifik, namun apabila tidak memiliki kapasitas seperti ketersediaan kapal dan pesawat udara, maka kewenangan tersebut hanya di atas kertas saja.

\section{SIMPULAN}

Berdasarkan pembahasan, maka perwujudan good order at sea di sepanjang ALKI II merupakan kewajiban negara sesuai UNCLOS 1982 dan aturan hukum internasional lainnya. Pemerintah Indonesia mengatur perlintasan di ALKI melalui Peraturan Pemerintah Nomor 37 Tahun 2002 tentang Hak Dan Kewajiban Kapal Dan Pesawat Udara Asing Dalam Melaksanakan Hak Lintas Alur Laut Kepulauan Melalui Alur Laut Kepulauan Yang Ditetapkan. Dalam perwujudan tersebut, TNI AL melalui Komando Armada II melakukan berbagai upaya sesuai kerangka tugas TNI AL melalui OMP dan OMSP. Kapasitas Komando Armada II sudah terbukti berkontribusi utama terhadap perwujudan good order at sea di ALKI II. Sehingga perlu adanya pengakuan dan dukungan yang lebih luas, mengingat keberadaan ALKI II akan semakin penting sebagai jalur navigasi internasional ke depan. 
158 I Gde Padang Suryawan, Suharto Ladjide, Sayed Fauzan Riyadi, Peran Tentara Nasional ...

\section{DAFTAR PUSTAKA}

Amiruddin dan Asikin, Zainal. 2003. Pengantar Metode Penelitian Hukum. Jakarta: Raja Grafindo Persada.

Bateman, Sam, Ho, Joshua dan Chan, Jane. 2009. "Good Order at Sea in Southeast Asia”. RSIS Policy Paper.

Handini, Wulan Pri dan Risdiarto, Danang. 2019. "Kedaulatan Wilayah Udara Di Atas Alur Laut Kepulauan Indonesia (ALKI)". Jurnal Rechts Vinding Volume 8, Nomor 2, Agustus 2019.

Komando Armada II. 2020. Laporan dan Evaluasi Pelaksanaan Operasi TNI/TNI AL Semester 2 TA 2020.

Muhjiddin, Atje Misbach. 1993. Status Hukum Perairan Kepulauan Indonesia dan Hak Lintas Kapal Asing. Bandung: Penerbit Alumni.

Sunggono, Bambang. 2001. Metode Penelitian Hukum. Jakarta: Raja Grafindo Persada.

Till, Geoffrey. 2018. Seapower: A Guide for the Twenty-First Century (4th ed.). Routledge.

Undang-Undang Nomor 17 Tahun 1985 tentang Pengesahan United Nations Convention On The Law of The Sea (Konvensi Perserikatan Bangsa-Bangsa Tentang Hukum Laut)

Undang-Undang Nomor 34 Tahun 2004 tentang Tentara Nasional Indonesia

Peraturan Pemerintah Nomor 37 Tahun 2002 tentang Hak dan Kewajiban Kapal dan Pesawat Udara Asing Dalam Melaksanakan Hak Lintas Alur Laut Kepulauan Melalui Alur Laut Kepulauan Yang Ditetapkan.

Keputusan Panglima Tentara Nasional Indonesia Nomor Kep/503/V/2018 tentang Doktrin TNI Angkatan Laut Jalesveva Jayamahe

Keputusan Panglima TNI Nomor Kep/1067/XII/2016 tentang Petunjuk Operasi Pengamanan Alur Laut Kepulauan Indonesia 